\title{
Right Kidney Mini-Invasive Living Donor Nephrectomy: A Safe and Efficient Alternative
}

\author{
Lucas Broudeur $^{a}$ Georges Karam ${ }^{a}$ Reshma Rana Magar ${ }^{b}$ Pascal Glemain ${ }^{a}$ \\ Thomas Loubersac $^{a} \quad$ Arthur Fosse $^{a} \quad$ Stéphane De Vergie $^{a} \quad$ Ismaël Chelghafa \\ Marie-Aimée Perrouin-Verbe ${ }^{a}$ Jérôme Rigaud ${ }^{a} \quad$ Julien Branchereau ${ }^{a-d}$ \\ aDepartment of Urology and Transplantation Surgery, University Hospital Center, Nantes, France;

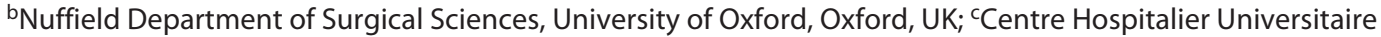 \\ de Nantes, Institut de Transplantation Urologie Néphrologie (ITUN), Nantes, France; ${ }^{\mathrm{d} C e n t r e ~ d e ~ R e c h e r c h e ~ e n ~}$ \\ Transplantation et Immunologie UMR 1064, INSERM, Université de Nantes, Nantes, France
}

\section{Keywords}

Living donor nephrectomy · Right kidney · Hand-assisted laparoscopy

\begin{abstract}
Introduction: Right kidney living donor transplantation is considered more difficult and associated with more complications. The objective was to evaluate donor safety and graft function of right hand-assisted laparoscopic donor nephrectomy (HALDN). Methods: A total of 270 consecutive HALDN procedures have been performed in our institution up to April 2017. We retrospectively compared the outcomes of right-sided nephrectomy (R-HALDN) to left-sided nephrectomy (L-HALDN) to evaluate donor safety and graft function of R-HALDN. Results: Sixty-seven right kidneys were removed for functional asymmetry in favour of left kidney (35/67) or left kidney multiple arteries (28/67). Among the donors, neither conversion to open surgery nor preoperative blood transfusion was necessary. There was no significant difference in operative time, compared to L-HALDN group
\end{abstract}

(170 $\pm 37 \mathrm{~min}$ vs. $171 \pm 32 \mathrm{~min} ; p$ value $=0.182)$. Warm ischaemia time was significantly longer for R-HALDN (4.0 \pm 1.6 $\min$ vs. $3.0 \pm 1.7 \mathrm{~min} ; p<0.001)$. There was no significant difference in terms of post-operative complications and serum $\mathrm{Cr}$ levels. Among the recipients, there were no graft venous thrombosis. There was no significant difference in delayed graft function ( 3 for R-HALDN group and 8 for L-HALDN group; $p$ value $=0.847$ ), serum $C r$ levels, and graft survival. Conclusion: R-HALDN is a safe procedure for kidney donors, with excellent graft function for the recipients, compared to L-HALDN.

(c) 2020 S. Karger AG, Basel

\section{Introduction}

Renal transplantation is the preferred treatment for ESRD. Living donor nephrectomy has provided a solution to the growing demand for renal transplants. This procedure requires maximum security for donors, who are exposed to high-risk surgery with no personal medical karger@karger.com

www.karger.com/uin

Karger ${ }^{\prime}=$
(C) 2020 S. Karger AG, Basel

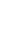

Lucas Broudeur

Department of Urology and Transplantation Surgery

University Hospital Center, 1 Place Alexis Ricordeau

FR-44093 Nantes Cedex 03 (France)

lucas.broudeur@gmail.com 
benefit and whose short-term and long-term state of health constitutes a major concern [1]. Laparoscopic techniques have been shown to be superior to open surgery in terms of post-nephrectomy morbidity, length of hospital stay, and quality of life for the donor [2, 3], while ensuring similar graft function [4]. Laparoscopic nephrectomy has become the standard practice in Europe, with more than $96 \%$ of these procedures performed by laparoscopy in 2017 [5].

For a long time, right kidney transplantation was associated with a higher rate of complications such as graft thrombosis and graft loss related to the shorter right renal vein [6]. However, a minority of surgeons still prefer to use the right kidney owing to its simpler vascular anatomy related to the absence of the confluence of gonadal and adrenal veins. In addition, it also avoids the risk of splenic injury related to detachment of the upper pole of the left kidney [7].

Although the current approach consists of "leaving the better kidney" to the donor, left donor nephrectomy still remains largely predominant [5] and is chosen by default, even though it sometimes comprises a multiple arterial blood supply, and is also sometimes associated with a higher rate of ureteric complications [8]. In 2018, in France, although the number of living donor renal transplantations increased, the proportion of right nephrectomies tended to remain stable or even slightly decreased, accounting for $9-18 \%$ of all nephrectomies each year since 2010 [9].

In our centre, we retrieve the kidneys by transperitoneal hand-assisted laparoscopic donor nephrectomy (HALDN). The objective of this study was to evaluate right donor nephrectomy by HALDN in terms of safety for the donor and also to compare the short-term and long-term results of the procedure in donors and recipients with that of left donor nephrectomy.

\section{Materials and Methods}

Since 2002, we have performed donor nephrectomy by HALDN. All donor nephrectomies from donors above 18 years of age were reviewed up until April 2017, which corresponded to 270 consecutive procedures. Short-term and long-term data, with a post-transplant follow-up of at least 1 year, for donor-recipient pairs were collected retrospectively from a French multicentre DIVAT database. The data collected comprised donor and recipient characteristics, intraoperative, and post-operative data. The results were compared between the right kidney (R-HALDN) group and the left kidney (L-HALDN) group.

The operating time (OT) was defined as the skin-to-skin OT, and the warm ischaemia time (WIT) was defined as the time be- tween the start of graft renal artery clamping and cold serum perfusion. The cold ischaemia time was defined as the time between the start of cold serum perfusion of the transplant and arterial unclamping in the recipient's body. Delayed graft function (DGF) was defined as the need for at least 1 dialysis session during the first week post-transplantation. Post-operative donor complications were defined according to the Clavien-Dindo classification. Graft loss was defined as the need for the recipient to return to dialysis.

\section{Donors and HALDN Technique}

Preoperative work-up comprised standard clinical, immunological, morphological, and vascular assessment based on CT angiography. In addition to this assessment, 51Cr-EDTA renal scintigraphy was performed to measure glomerular filtration rate, and DMSA scintigraphy was performed to detect functional asymmetry between the 2 kidneys. The left kidney was systematically chosen for donor nephrectomy, except in the presence of functional asymmetry $>5 \%$ in favour of either the left kidney or multiple left renal arteries, or abnormalities on the right kidney.

The donor was in a lateral supine position. A Pfannenstiel 8-cm incision was sufficient to allow the surgeon to introduce his hand through the sealed inflatable cuff (Gelport Laparoscopic System ${ }^{\circledR}$ ). A first 10-mm trocar for the laparoscope was placed subcostally, guided by the operator's hand. A 5/12-mm trocar was then placed paramedian for the introduction of bipolar forceps or ultrasound scissors. Another 5-mm trocar was placed in the flank for the assistant's instruments, and another trocar was sometimes placed for right nephrectomies to allow retraction of the liver by self-retaining forceps. Left donor nephrectomy started with paracolic dissection, providing access to the retroperitoneum and perirenal space. The upper pole of the left kidney was first dissected from its adhesions with the spleen. The ureter was then dissected en bloc with the gonadal vein as far as the common iliac artery. The donor then received an intravenous injection of $25 \mathrm{IU} / \mathrm{kg}$ of heparin and 0.5 $\mathrm{mg}$ of nicardipine before exposing the renal pedicle. With the recipient anaesthetized in an adjacent room, the ureter and gonadal vein were ligated, and sectioned. The artery and then the vein were stapled with Endo-TA ${ }^{\circledR} 2.5 \mathrm{~mm}$ vascular forceps, and then cut. The kidney was then rapidly extracted via the hand-assisted incision, and then perfused with iced heparinised physiological saline $(5,000$ $\mathrm{IU} / \mathrm{L})$. For right donor nephrectomies, the ureter was dissected without the gonadal vein, the renal artery was sectioned behind the inferior vena cava guided by the operator's hand, and the renal vein was sectioned at the level of the inferior vena cava to ensure maximum length of the renal vein. During the implantation of right kidney, the recipient's external iliac vein was extensively dissected in order to mobilize it and to perform anastomosis without traction.

\section{Statistical Analysis}

Data were expressed as the mean (standard deviation) or number (percentage), as appropriate. Quantitative variables were compared by Student's $t$ test, and variables with a non-normal distribution were compared by a Mann-Whitney $U$ test. A KolmogorovSmirnov test was used to determine the normal distribution of samples. A $\chi^{2}$ test was used for qualitative data. Analysis of graft survival in recipients was performed according to the Kaplan-Meier method, and survival curves were compared by a log-rank test. A $p$ value $<0.05$ was considered to be statistically significant. 
Table 1.Donor and recipient characteristics

\begin{tabular}{|c|c|c|c|}
\hline & $\begin{array}{l}\text { Right kidney } \\
(n=67)\end{array}$ & $\begin{array}{l}\text { Left kidney } \\
(n=203)\end{array}$ & $p$ value \\
\hline \multicolumn{4}{|l|}{ Donor } \\
\hline Age (mean $[\mathrm{DS}])$, years & $47.4(12.3)$ & $47.0(11.3)$ & 0.823 \\
\hline Sex (men), $n(\%)$ & $23(34.3)$ & $89(43.8)$ & 0.208 \\
\hline $\mathrm{BMI}, \mathrm{kg} / \mathrm{m}^{2}$ (mean [DS]) & $23.7(2.8)$ & $24.5(3.2)$ & 0.075 \\
\hline Smoking, $n(\%)$ & $15(22.7)$ & $59(29.4)$ & 0.344 \\
\hline Preoperative SCr (mean [DS]), $\mu \mathrm{mol} / \mathrm{L}$ & $68.1(11.1)$ & $70.9(12.9)$ & 0.111 \\
\hline EDTA GFR (mean [DS]), $\mathrm{mL} / \mathrm{min}$ & $104.1(16.4)$ & $106.2(18.3)$ & 0.422 \\
\hline \multicolumn{4}{|l|}{ Recipient } \\
\hline Age (mean $[\mathrm{DS}]$ ), years & $45.8(13.8)$ & $39.5(12.8)$ & 0.520 \\
\hline Sex (men), $n(\%)$ & $42(62.7)$ & $119(58.6)$ & 0.653 \\
\hline BMI (mean [DS]), $\mathrm{kg} / \mathrm{m}^{2}$ & $23.7(3.5)$ & $22.6(3.8)$ & 0.868 \\
\hline Smoking, $n(\%)$ & $8(17.4)$ & $30(23.4)$ & 0.497 \\
\hline \multicolumn{4}{|l|}{ Cause of ESRD, $n(\%)$} \\
\hline CIN from urologic disease & $8(11.9)$ & $21(10.3)$ & 0.822 \\
\hline CIN from other cause & $23(34.3)$ & $86(42.4)$ & 0.255 \\
\hline Chronic glomerulonephritis & $25(37.3)$ & $59(29.1)$ & 0.225 \\
\hline Vascular cause & $3(4.5)$ & $9(4.4)$ & 0.988 \\
\hline Diabetes & $1(1.5)$ & $9(4.4)$ & 0.459 \\
\hline Unknown & $7(10.4)$ & $19(9.4)$ & 0.813 \\
\hline \multicolumn{4}{|l|}{ Kind of dialysis, $n(\%)$} \\
\hline Pre-emptive kidney transplantation & $23(34.3)$ & $82(40.4)$ & 0.452 \\
\hline Haemodialysis & $35(52.2)$ & $101(49.8)$ & 0.832 \\
\hline Peritoneal dialysis & $9(13.4)$ & $20(9.9)$ & 0.579 \\
\hline Dialysis duration (mean [DS]), days & $423(367)$ & $868(922)$ & 0.093 \\
\hline \multicolumn{4}{|l|}{ Kidney transplantation rank, $n(\%)$} \\
\hline 1 st & $57(85.1)$ & $178(87.7)$ & 0.743 \\
\hline 2 nd & $9(13.4)$ & $22(10.8)$ & 0.145 \\
\hline $3 \mathrm{rd}$ & $1(1.5)$ & $3(1.5)$ & 1.000 \\
\hline
\end{tabular}

SCr, serum Cr; EDTA, 99m-Technetium diethylenetriamine penta-acetic acid; CIN, chronic interstitial nephritis.

\section{Results}

Criteria for the Choice of the Right Kidney

Among the 270 HALDN procedures performed, 67 (24.8\%) were right kidneys (R-HALDN) and 203 (75.2\%) were left kidneys (L-HALDN). The criteria supporting the use of the right kidney were functional asymmetry in favour of the left kidney in $35 / 67$ cases $(52.2 \%)$, the presence of multiple arteries on the left kidney in 28/67 cases (41.8\%), the presence of a $5-\mathrm{cm}$ renal cyst in 1 case, the presence of a vascular abnormality in 2 cases (right renal artery aneurysm and left-sided inferior vena cava resulting in a short left renal vein), and 1 case in which the implantation of a right kidney was more favourable in the third renal transplant position.

\section{General and Demographic Characteristics}

The detailed general and demographic characteristic data of donors and recipients are presented in Table 1. No significant difference in terms of general or demographic data was observed between the 2 groups of donors and the 2 groups of recipients.

\section{Donors}

The results concerning donors are presented in Table 2. No significant difference in terms of mean OT was observed between the 2 groups: $170.4( \pm 36.8) \mathrm{min}$ in the R-HALDN group and $171.5( \pm 31.8) \mathrm{min}$ in the L-HAL$\mathrm{DN}$ group $(p=0.182)$. Multiple arteries were present in 6 (9.0\%) right donor kidneys and 34 (16.7\%) left donor kidneys, without significant difference between the 2 groups $(p=0.164)$. Mean warm ischaemia time was significantly longer in the R-HALDN group, compared to the L-HALDN group: $4.0( \pm 1.7) \mathrm{min}$ and $3.0( \pm 1.7) \mathrm{min}$, respectively $(p<0.001)$. No conversion to open surgery and no intraoperative blood transfusion were necessary. The mean length of hospital stay was $4.3( \pm 1.3)$ days in the R-HALDN group and $4.5( \pm 1.2)$ days in the L-HALDN group. A 
Table 2. Donor outcomes and follow-up

\begin{tabular}{lccc}
\hline & $\begin{array}{l}\text { Right kidney } \\
(n=67)\end{array}$ & $\begin{array}{l}\text { Left kidney } \\
(n=203)\end{array}$ & $p$ value \\
\hline OT (mean [DS]), min & $170.4(36.8)$ & $171.5(31.8)$ & 0.182 \\
WIT (mean [DS]), min & $4.0(1.7)$ & $3.0(1.7)$ & $<0.001$ \\
Multiple arteries, $n(\%)$ & $6(9.0)$ & $34(16.7)$ & 0.164 \\
Open conversion, $n$ & 0 & 0 & - \\
Blood transfusion, $n$ & 0 & 1 & - \\
Hospital LOS (mean [DS]), days & $4.3(1.3)$ & $4.5(1.2)$ & 0.168 \\
SCr (mean [DS]), $\mu$ mol/L & & & \\
$\quad$ At discharge & $103(20)$ & $107(22)$ & 0.176 \\
$\quad 1$ month & $99(18)$ & $106(20)$ & 0.088 \\
$\quad 1$ year & $13(19)$ & $101(18)$ & 0.501 \\
Post-operative complication, $n(\%)$ & 0 & $50(24.6)$ & 0.380 \\
$\quad$ Grade I & 0 & $5(2.5)$ & 0.195 \\
$\quad$ Grade II & 0 & $4(2.0)$ & 0.247 \\
$\quad$ Grade $\geq$ IIIa & 1 & - \\
CKD $(n)$ & & 1 & \\
\hline
\end{tabular}

OT, operative time; WIT, warm ischaemia time; LOS, length of stay; SCr, serum Cr.

Table 3. Recipient outcomes and follow-up

\begin{tabular}{lccc}
\hline & $\begin{array}{l}\text { Right kidney } \\
(n=67)\end{array}$ & $\begin{array}{l}\text { Left kidney } \\
(n=203)\end{array}$ & $p$ value \\
\hline Graft position, $n(\%)$ & & & \\
$\quad$ Ipsilateral & $61(91.0)$ & $155(76.4)$ & - \\
$\quad$ Contralateral & $4(6.0)$ & $43(21.2)$ & 0.004 \\
3rd graft position & $2(3.0)$ & $5(2.5)$ & - \\
CIT (mean [DS]), min & $93.5(28.9)$ & $92.5(27.8)$ & 0.674 \\
Anastomosis time (mean [DS]), min & $28.9(5.5)$ & $28.2(5.0)$ & 0.537 \\
DGF (excluding pre-emptive graft), $n(\%)$ & $3 / 44(6.8)$ & $8 / 121(6.6)$ & 0.847 \\
Post-operative complication, $n(\%)$ & $6(9.0)$ & $42(20.7)$ & 0.029 \\
$\quad$ Graft vascular thrombosis & 0 & 0 & - \\
Bleeding/hematoma & $3(4.5)$ & $13(6.4)$ & 0.563 \\
Lymphocele & $2(3.0)$ & $10(4.9)$ & 0.736 \\
Ureteral leak & $1(1.5)$ & $4(2.0)$ & 1.000 \\
Ureteral stenosis & 0 & $2(1.0)$ & 0.995 \\
Vesicoureteral reflux & 0 & $13(6.4)$ & 0.034 \\
SCr (mean [DS]), $\mu$ mol/L & & & \\
3 months & $125(31)$ & $120(33)$ & 0.243 \\
6 months & $127(44)$ & $120(32)$ & 0.232 \\
1 year & $120(29)$ & $123(39)$ & 0.859 \\
5 years & $116(30)$ & $125(57)$ & 0.380 \\
1-year graft survival, $n(\%)$ & $67(100)$ & $201(99.0)$ & 1.000 \\
Global graft survival, $n(\%)$ & $64(95.5)$ & $183(90.1)$ & 0.172 \\
\hline CIT, cold ischaemia time; DGF, delayed graft function; SCr, serum Cr. & \\
\hline
\end{tabular}

grade I post-operative complication was observed in 13 (19.4\%) donors of the R-HALDN group and 50 (24.6\%) donors of the L-HALDN $(p=0.380)$ group. In the LHALDN group, there were 5 grade II complications (one case of acute urinary retention, 2 cases of urinary tract infection, 1 wound infection treated by antibiotics, and 1 post-operative transfusion) and 4 grade $\geq$ IIIA complications ( 2 cases of surgical scar revision due to incisional hernia, 1 early surgical revision for wound infection, and 1 grade $\mathrm{V}$ complication 4 years after kidney donation in a context of acute bowel obstruction secondary to adhesions). 


\section{Recipients}

Results concerning procedures, post-operative followup, and long-term follow-up are presented in Table 3. No significant difference was observed between the 2 groups in terms of post-operative DGF, with 3 cases of DGF in the R-HALDN group and 8 cases of DGF in the L-HAL$\mathrm{DN}$ group $(p=0.847)$. A higher post-operative surgical complication rate was observed in the L-HALDN group (20.7\%) compared to the R-HALDN group $(9.0 \%$; $p=$ 0.029 ). No case of graft vascular thrombosis was observed in either of the 2 groups. No significant difference in terms of serum $\mathrm{Cr}$ during short-term follow-up was observed between the 2 groups at $3,6,12$, months, and 5 years. The 1-year graft survival rate was $100 \%$ for the RHALDN group and $99 \%$ for the L-HALDN group ( $p=$ $1.000)$. The cause of 1 -year graft loss was hyperacute rejection in 1 case and multiple organ dysfunction syndrome, following acute coronary syndrome 1 month after transplantation, in another case. Overall survival with a mean follow-up of $5.6( \pm 4.0)$ years for the R-HALDN group and $5.3( \pm 3.8)$ years for the L-HALDN group was 95.5 and $90.1 \%$, respectively $(p=0.172)$. Analysis of graft survival by comparing the R-HALDN and L-HALDN groups did not reveal any significant difference between the 2 groups $(p=0.144)$.

\section{Discussion/Conclusion}

Laparoscopic techniques have become the predominant practice for living donor nephrectomy. The initial experience of right LLDN was associated with a high rate of graft thrombosis of up to $56 \%[6,7,10]$, which was probably related to the shortness of the right renal vein. This resulted in the exclusion of right kidney donors from the benefits of minimally invasive laparoscopic techniques [7]. A recent multicentre study showed that lowvolume centres performed a lower rate of right donor nephrectomy (17 vs. $29 \%$ ) and predominantly performed these procedures by open surgery ( 53 vs. $13 \%$ ), compared to high-volume centres [11].

In our series, $24.8 \%$ of donor nephrectomies were right kidneys, and all were performed by HALDN. The main limitation of our study is its retrospective and monocentric design with procedures performed in an experienced transplant centre almost exclusively by single surgeon. We consider that hand-assisted donor nephrectomy facilitates dissection by ensuring controlled traction of the vascular structures, allowing safer procedures such as vascular stapling and easier control of intraoperative bleeding.

Right Kidney Living Donor Nephrectomy
Management of the renal vein during right kidney transplantation is technically challenging during both donor nephrectomy and implantation. However, a maximum vein length can be preserved during venous stapling by using an appropriate technique as the use of Endo$\mathrm{TA}^{\circledR}$ vascular forceps for venous stapling with soft traction of the kidney by the surgeon's hand during handassisted procedures [12]. Various techniques have also been proposed to ensure tension-free venous anastomosis during kidney implantation, with a harmonious course of the short renal vein in order to decrease the risk of thrombosis. Lind and Ijzermans [13] described a method consisting of complete dissection of the recipient external iliac vein in order to ensure optimal mobilization and tension-free anastomosis; this is the method that we use in our centre.

The results of the present series suggest that right donor nephrectomy by HALDN is as safe for donors as left donor nephrectomy. Some authors consider that right LLDN is easier than left LLDN $[7,14]$ due to easier exposure and release of the perirenal space and the absence of gonadal and adrenal venous branches. A significantly shorter OT compared to left donor nephrectomy has been reported in some series [14-16]; this has further been confirmed in a recent meta-analysis [17] where there was a 13-min mean reduction in the OT. No difference in OT was observed in our series. Some series [14, 18] have reported cases of conversion due to bleeding following a vascular injury, but with no significant difference compared to left nephrectomy. No case of conversion or intraoperative transfusion was observed in our series.

With regard to the short-term and long-term functional results in the recipients, no significant difference was observed in our study between the right and left kidneys in terms of DGF, post-operative serum Cr, 1-year graft survival and overall survival. No case of graft vascular thrombosis was observed. These results are consistent with those of most studies [14-20], except for studies [21, 22] based on national registries in which Khalil [21] reported a higher rate of vascular thrombosis and DGF for right kidneys. However, this difference was minor (graft thrombosis: 0.8 vs. $1.1 \%$ and DGF: 4.2 vs. $5.7 \%$ ) and did not affect the 1-year graft survival. Redfield et al. [22] reported right kidney as a risk factor of DGF, but the difference was small and may be due to longer operative time and right kidney was not associated with increased graft loss rate.

The results of the present study suggest that hand-assisted laparoscopic right donor nephrectomy carried out 
by using Endo-TA ${ }^{\circledR}$ forceps stapling, is a safe technique. This procedure is not associated with any additional complications for the recipient and has been seen to provide excellent short- and long-term functional results. Right nephrectomy should not constitute a technical obstacle to the development of living donor kidney transplantation.

\section{Statement of Ethics}

The study was approval from the regional ethics committee (DC-2011-1939). A preliminary consent from patients regarding the collection and processing of data was obtained, and data were analysed anonymously. Data were protected by French Information Commissioner's Office for data privacy declaration (CNIL No. 891735).

\section{Conflict of Interest Statement}

The authors have no conflicts of interest to declare.

\section{Funding Sources}

The authors have not had any funding for this study.

\section{Author Contributions}

L.B., G.K., J.R., and J.B.: design of the study; L.B., I.C., A.F., and T.L.: data collection; P.G., G.K., J.B., and M.-A.P.-V.: data analysis; S.D.V. and M.-A.P.-V.: statistical analysis; L.B., R.R.M., and J.B.: manuscript realization.

\section{References}

1 Muzaale AD, Massie AB, Wang MC, Montgomery RA, McBride MA, Wainright JL, et al. Risk of end-stage renal disease following live kidney donation. JAMA. 2014;311(6):57986.

2 Wilson CH, Sanni A, Rix DA, Soomro NA. Laparoscopic versus open nephrectomy for live kidney donors. Cochrane Database Syst Rev. 2011;(11):CD006124.

3 Andersen $\mathrm{MH}$, Mathisen L, Veenstra M, Oyen O, Edwin B, Digernes R, et al. Quality of life after randomization to laparoscopic versus open living donor nephrectomy: longterm follow-up. Transplantation. 2007;84(1): 64-9.

4 Troppmann C, Ormond DB, Perez RV. Laparoscopic (vs open) live donor nephrectomy: a UNOS database analysis of early graft function and survival. Am J Transplant. 2003; 3(10):1295-301.

5 Klop KW, Dols LF, Kok NF, Weimar W, Ijzermans JN. Attitudes among surgeons towards live-donor nephrectomy: a European update. Transplantation. 2012;94(3):263-8.

6 Mandal AK, Cohen C, Montgomery RA, Kavoussi $\mathrm{LR}$, Ratner LE. Should the indications for laparascopic live donor nephrectomy of the right kidney be the same as for the open procedure? Anomalous left renal vasculature is not a contraindiction to laparoscopic left donor nephrectomy. Transplantation. 2001; 71(5):660-4.

7 Lind MY, Hazebroek EJ, Hop WC, Weimar W, Jaap Bonjer H, IJzermans JN. Right-sided laparoscopic live-donor nephrectomy: is reluctance still justified? Transplantation. 2002; 74(7):1045-8.
8 Carter JT, Freise CE, McTaggart RA, Mahanty HD, Kang SM, Chan SH, et al. Laparoscopic procurement of kidneys with multiple renal arteries is associated with increased ureteral complications in the recipient. Am J Transplant. 2005;5(6):1312-8.

9 Annual report of the French Biomedicine Agency's kidney transplant activity [internet]. 2018. Available from: https://rams. agence-biomedecine.fr/greffe-renale

10 Breda A, Veale J, Liao J, Schulam PG. Complications of laparoscopic living donor nephrectomy and their management: the UCLA experience. Urology. 2007;69(1):49-52.

11 Ravaioli M, Capocasale E, Furian L, De Pace $\mathrm{V}$, Iaria M, Spagnoletti G, et al. Are there any relations among transplant centre volume, surgical technique and anatomy for donor graft selection? Ten-year multicentric Italian experience on mini-invasive living donor nephrectomy. Nephrol Dial Transplant. 2017; 32(12):2126-31.

12 Wolf JS, Tchetgen MB, Merion RM. Handassisted laparoscopic live donor nephrectomy. Urology. 1998;52(5):885-7.

13 Lind MY, Ijzermans JN. Re: laparoscopic live donor right nephrectomy: a new technique with preservation of vascular length. J Urol. 2002;168(5):2127.

14 Dols LF, Kok NF, Alwayn IP, Tran TC, Weimar W, Ijzermans JN. Laparoscopic donor nephrectomy: a plea for the right-sided approach. Transplantation. 2009;87(5):745-50.

15 Minnee RC, Bemelman WA, Maartense S, Bemelman FJ, Gouma DJ, Idu MM. Left or right kidney in hand-assisted donor nephrectomy? A randomized controlled trial. Transplantation. 2008;85(2):203-8.
16 Saad S, Paul A, Treckmann J, Nagelschmidt M, Heiss M, Arns W. Laparoscopic live donor nephrectomy for right kidneys: experience in a German community hospital. Surg Endosc. 2008;22(3):674-8.

17 Wang K, Zhang P, Xu X, Fan M. Right versus left laparoscopic living-donor nephrectomy: a meta-analysis. Exp Clin Transplant. 2015; 13(3):214-26.

18 Kashiwadate T, Tokodai K, Amada N, Haga I, Takayama T, Nakamura A, et al. Right versus left retroperitoneoscopic living-donor nephrectomy. Int Urol Nephrol. 2015;47(7): 1117-21.

19 Ciudin A, Musquera M, Huguet J, Peri L, Alvarez-Vijande JR, Ribal MJ, et al. Transposition of iliac vessels in implantation of right living donor kidneys. Transplant Proc. 2012; 44(10):2945-8.

20 Hoda MR, Greco F, Wagner S, Heynemann $\mathrm{H}$, Fornara P. Prospective, nonrandomized comparison between right- and left-sided hand-assisted laparoscopic donor nephrectomy. Transplant Proc. 2011;43(1):353-6.

21 Khalil A, Mujtaba MA, Taber TE, Yaqub MS, Goggins W, Powelson J, et al. Trends and outcomes in right vs. left living donor nephrectomy: an analysis of the OPTN/UNOS database of donor and recipient outcomes: should we be doing more right-sided nephrectomies? Clin Transplant. 2016;30(2):145-53.

22 Redfield RR, Scalea JR, Zens TJ, Muth B, Kaufman DB, Djamali A, et al. Predictors and outcomes of delayed graft function after living-donor kidney transplantation. Transplant Int. 2015;29(1):81-7. 